\title{
A ATIVIDADE REGULATÓRIA DO ESTADO E SEUS FUNDAMENTOS
}

\author{
GOVERNMENT REGULATORY ACTIVITY AND ITS \\ FUNDAMENTALS
}

Recebido em 21/11/2017

Aprovado em 19/01/2018

ARTUR CARNAUBA GUERRA SANGREMAN LIMA

RESUMO: Sob a influência de um modelo de regulação adotado internacionalmente, notadamente nos Estados Unidos da América e na Comunidade Europeia, a atividade regulatória do Estado estruturou-se no Brasil por meio de entidades administrativas dotadas de autonomia reforçada perante o poder central e especializadas em determinado setor. Inaugurado na década de 1990, o formato da regulação estatal brasileiro representa uma mudança de paradigma da atuação estatal, que se caracteriza por uma intervenção estatal prioritariamente indireta. Nesse contexto, afigura-se importante uma análise acerca dos fundamentos que estruturam a regulação estatal, na medida em que uma atuação neutra, técnica, setorizada e independente das agências reguladoras conforma-se como verdadeira garantia para os administrados.

PALAVRA-CHAVE: atividade regulatória, regulação estatal, fundamentos, neutralidade, independência.

\begin{abstract}
Under the influence of a regulatory framework adopted worldwide, notably in the United States of America and in the European Community, government regulatory activity in Brazil has established itself through administrative entities that regulate specific industries and have enhanced autonomy before the central government. The Brazilian regulatory framework was launched in the 1990s and it meant a paradigm shift in government action, thenceforth characterized by primarily indirect intervention. In this context, it is important to analyze the fundamentals that shape government regulation, since impartial, technical, and independent regulatory agencies are truly a reassurance and a protection for those industries under their supervision.
\end{abstract}

KEYWORDS: regulatory activity, government regulation, fundaments, neutrality, independence.

${ }^{1}$ Mestre em Direito pela UFAL. Procurador do município de Maceió, Advogado. 


\section{INTRODUÇÃO}

O modelo de agências reguladoras foi idealizado no Brasil nos anos 1990 com o objetivo de fortalecer a especialização e o conhecimento técnico no processo de construção da decisão estatal, ocasionado por um movimento de redução da intervenção direta do Estado no domínio econômico e na prestação de serviços públicos.

Nessa caminhada, principalmente sob a influência da experiência norte-americana, foram criadas autarquias regulatórias, submetidas a regime jurídico especial, a fim de atuarem em setores específicos. Para tanto, percebeu-se a necessidade de que as agências fossem dotadas de independência política, administrativa, técnico-decisional e normativa.

Busca-se, então, analisar a diversas nuances que conformam a regulação estatal, inicialmente por intermédio de uma abordagem quanto ao contexto jurídico de sua consolidação no ordenamento jurídico pátrio, sem olvidar a necessidade de uma contextualização do tema no panorama internacional, e, em seguida, mediante um estudo dos diferentes fundamentos da atividade regulatória do Estado.

\section{EVOLUÇÃO DA REGULAÇÃO ESTATAL}

\subsection{A REGULAÇÃO NOS ESTADOS UNIDOS DA AMÉRICA E NA COMUNIDADE EUROPEIA}

A concepção de agências reguladoras no Brasil, criadas com o fim do monopólio estatal sobre determinadas atividades e após a abertura do mercado para o capital estrangeiro, sofreu forte influência do modelo norte-americano.

Nos Estados Unidos da América, a Interstate Commerce Commission (ICC) é comumente apontada como a primeira agência reguladora independente. Sua criação, em 1887, se deu com a finalidade de regular serviços interestaduais de transporte ferroviário, inaugurando uma postura mais interventiva no âmbito daquele país (BINENBOJM, 2006, p. 243), notadamente sobre a atividade econômica. 
Entretanto, foi com a Grande Depressão de 1929, que trouxe à tona as falhas do modelo liberal então praticado, apontando para a necessidade de uma maior intervenção do Estado na economia, e a adoção de um pacote de medidas de superação da crise, conhecido como New Deal, que a atividade regulatória ganhou força (GOMES, 2006, p. 24). Nesse momento histórico, inicia-se um movimento no sentido de conferir ao Executivo as funções de elaborar normas (rulemaking 2 ) e de julgamento (adjudication ${ }^{3}$ ) (LIMA, 2013, p. 112).

A questão começou a receber contornos definitivos em 1946, com a aprovação da APA - Administrative Procedure Act (Lei de Procedimentos Administrativos). A APA consagrou a criação das agências reguladoras, dotadas de poderes legislativos, executivos e jurisdicionais, que podem ser segmentadas em agências executivas e agências independentes, a depender de sua vinculação com o Poder Central (CUSTOS, 2009, p. 195).

Burnham (2006, p. 195-196) aponta três razões essenciais para a criação das agências reguladoras. Em primeiro lugar, trata-se de entidades dotadas de expertise em área específica, capazes de dar soluções melhores aos problemas que lhes são afetos (noutras palavras, Executivo, Legislativo e Judiciário não possuem aptidão técnica para lidar com determinadas questões no mesmo nível qualitativo das agências). A regulação de determinadas áreas demanda alto nível de conhecimento e flexibilidade para reagir rapidamente às oscilações da economia e do mercado. Em segundo lugar, a especialização proporciona ganhos em eficiência. Por último, o distanciamento político permite a adoção de decisões mais consistentes e racionais.

Apesar do fortalecimento da regulação ao longo do tempo, ganha espaço, na década de 1970, o fenômeno denominado de desregulação (deregulation), que promoveu o aumento do controle judicial sobre as agências reguladoras (LIMA, 2013, p. 116). Desde o julgamento do caso Chevron v. Natural Resources Defense Council pela Suprema Corte Norte-Americana, em 1984, percebe-se a consolidação da intervenção jurisdicional sobre a atuação das agências, sobretudo para aferir a observância dos procedimentos estabelecidos pela APA no que concerne à expedição de atos normativos e ao exercício de sua função judicante.

As agências reguladoras norte-americanas possuem como características marcantes as competências de editar normas e de julgar conflitos (LIMA, 2013, p. 129). Já se disse

2 USA. APA - Administrative Procedure Act. Título 5, Parte I, Capítulo 5, Subcapítulo II, § 553.
3 USA. APA - Administrative Procedure Act. Título 5, Parte I, Capítulo 5, Subcapítulo II, § 554. 
anteriormente que tais funções se conformariam como quase-legislativas e quase-judiciais, visão que não prevalece atualmente. Hoje se admite que as agências possuem verdadeira delegação para legislar e julgar, de modo que a doutrina da não delegação resta superada (POSNER; VERMEULE). Com efeito, vislumbra-se a segmentação, como já mencionado, em agências executivas e agências independentes, a depender da (in)dependência em relação ao Poder Central, consubstanciada primordialmente na possibilidade de o Chefe do Executivo exonerar ad nutum seus dirigentes (CUSTOS, 2009, p. 195).

Por fim, mostra-se pertinente pontuar que a função de elaborar normas das agências reguladoras norte-americanas não se caracteriza apenas como poder, mas também como um processo (LIMA, 2013, p. 130), o qual pode seguir diferentes modelos.

$\mathrm{O}$ primeiro é denominado de informal rulemaking. O procedimento de elaboração inicia-se com a publicação da proposta do ato normativo, acompanhada de um convite para que o público interessado se manifeste sobre a matéria; ao final, promulga e publica a versão final do documento (BURNHAM, 2006, p. 196). Importante observar que as discussões e comentários devem ser levados em consideração nessa versão final, sem ignorar nenhum ponto de vista, isto é, deverá ser ofertada uma resposta para cada comentário, seja para afastálo ou para acolhê-lo, a fim de demonstrar o empenho da agência em encontrar uma decisão razoável (BURNHAM, 2006, p. 197).

O segundo modelo é denominado de formal rulemaking. Em que pese a diferenciação de nomenclatura, os procedimentos se assemelham, porém, deve ser obrigatoriamente adotado quando o Legislativo assim dispuser (BURNHAM, 2006, p. 197). Este procedimento, denominado de formal, possui as mesmas etapas do anterior (informal), acrescido de um rito de audiências de produção de provas e de julgamento de elaboração da norma pelos chamados Administrative Law Judges (autoridades administrativas independentes), os quais não integram o Poder Judiciário (MESSITE, 2015).

É possível, ainda, que as agências editem normas com a finalidade de conferir interpretação para dispositivos legais já existentes, o que não significa propriamente o exercício de função legislativa, dispensando qualquer procedimento específico, bem como é possível que as normas sejam criadas em decorrência de um julgamento administrativo, tal como um precedente judicial (LIMA, 2013, p. 131). 
Diferentemente do caminho trilhado pelos Estados Unidos, em que a implantação da atividade regulatória estatal prestou-se inicialmente a limitar o liberalismo econômico, buscando corrigir inconsistências do sistema, o modelo de regulação europeu trilha o caminho da redução da intervenção do Estado na economia (BINENBOJM, 2006, p. 244), em especial com o intuito de proporcionar a quebra dos monopólios públicos em determinados segmentos da atividade econômica e da prestação de serviços públicos (MARCOU, 2009, p. 14). Sob este aspecto, o modelo de regulação brasileiro se assemelha mais ao europeu.

No início do último quarto do século $\mathrm{XX}$, a concepção prevalente ainda era a de intervenção direta do Estado na economia e na prestação de serviços públicos, ficando o Poder Público em posse de atividades consideradas como fundamentais para a manutenção do bem-estar da população. Nessa esteira, o regime de monopólio implicava a inexistência dos problemas oriundos da concorrência, haja vista a ausência de agentes diversos no desempenho dos serviços. A atividade regulatória atua exatamente neste campo, de maneira a separar as funções de regulação e de prestação, que deixam de concentrar-se numa mesma pessoa (MOTTA, 2003, p. 75).

Em ensaio sobre as autoridades independentes administrativas francesas, Auad (2004, p. 446) menciona que seu advento coincide com a crise do Estado Intervencionista, também nominado de Estado Social, de forma que se fez necessária a redução do aparato estatal, com a redução da intervenção direta sobre o domínio econômico, o que se deu através da desregulação, que "significa aumentar o campo das liberdades individuais através da diminuição de regras estatais à atividade do particular". Ademais, cumpre observar que o modelo adotado no país não seguiu a lógica da descentralização, ainda que se haja preservado a ausência de subordinação hierárquica em relação ao Poder Central (BADIN, 2004, p. 454).

Há uma relação importante entre a constituição da União Europeia e a proliferação das autoridades/entidades regulatórias independentes. O projeto comunitário passa pela supremacia do direito comunitário sobre a ordem jurídica de cada um dos países, tornando-se necessária a adaptação do direito posto em cada nação. A ideia de regulação independente, em virtude da neutralidade política, despontou como o modelo mais viável para a efetivação do direito supranacional e de políticas comunitárias (BINENBOJM, 2006, p. 245).

Assim, a instituição de agências reguladoras coloca-se na comunidade europeia como responsável por garantir uma isonomia de tratamento entre os operadores públicos e privados, 
bem como tem por finalidade favorecer a convergência dos diversos interesses das nações que compõem o bloco em matéria de regulação, notadamente em setores estratégicos como energia e transporte (MODERNE, 2009, p. 107-108).

Cumpre pontuar que a experiência regulatória europeia prestou-se não somente a realizar a intervenção direta do Estado sobre o domínio econômico (MARCOU, 2009, p. 39), mas buscou também a promoção de questões de interesse da coletividade, como serviços públicos, e a proteção de direitos fundamentais, seja em face de particulares, seja em face da própria atuação estatal (BINENBOJM, 2006, p. 247).

Atualmente, o conceito de agência reguladora europeia é amplo, abarcando todas aquelas que participam ativamente do exercício da função executiva mediante a adoção de atos que colaboram para a regulação de determinado setor (SZAPIRO, 2004, p. 1). Em meio a uma falta de princípios norteadores para a criação e o controle das agências, cada uma se submete a regramentos específicos, os quais resultam de negociações no respectivo âmbito setorial, circunstância que denota a heterogeneidade desses organismos descentralizados (SZAPIRO, 2004, p. 2). Contudo, há um eixo comum que recai sobre a necessidade de observar critérios como credibilidade, transparência, imparcialidade, independência, especialização técnica e controle (SZAPIRO, 2004, p. 3)

Por fim, há de se ressaltar que, no âmbito da União Europeia, a delegação de competência do nível nacional para um organismo descentralizado a nível comunitário conforma-se como uma opção, aplicando-se o princípio da subsidiariedade, isto é, somente quando os objetivos perseguidos não puderem ser satisfatoriamente alcançados pelos Estados membros (SZAPIRO, 2004, p. 3). Por conseguinte, nada obsta a criação de agências (ou autoridades administrativas independentes) individualmente pelos membros do bloco.

\subsection{O SURGIMENTO DAS AGÊNCIAS REGULADORAS NO PANORAMA NACIONAL}

Em âmbito nacional, a Administração Pública, adotando um viés social de implementação de direitos de caráter prestacional e, ao mesmo tempo, incumbindo-se de desempenhar atividades econômicas de grande relevância, sem prejuízo da função fiscalizatória que lhe é inerente, não mais conseguia desempenhar satisfatoriamente tantas atribuições, o que levou à abertura da economia e à criação de programas de desestatização. 
Explicita Bruno Miragem (2013, p. 61):

a regulação, no Brasil, surge como fenômeno decorrente da tendência de menor intervenção do Estado no mercado e na economia, passando de uma intervenção direta do Estado no domínio econômico, a partir da desestatização, pela mudança no modo de atuação estatal, por intermédio de atividade de mediação de interesses pelo estabelecimento de normatização e estruturas de controle e fiscalização, as quais são protagonistas da atividade regulatória estatal. Caracteriza-se, portanto, como fenômeno que na realidade norte-americana reconhece-se como desregulation, caracterizando lá uma menor intervenção estatal por intermédio do modo típico de atuação do Estado, qual seja, de regulação jurídica da atividade econômica.

Após a crise econômica vivenciada na década de 1980, repensou-se o papel do Estado na economia, no sentido de promover sua retirada da intervenção direta sobre o domínio econômico, abandonando a ideia de Estado empresário, por meio das desestatizações e flexibilizações de monopólios, passando para o modelo de Estado regulador. A criação de agências para desempenhar um papel regulatório buscava conferir maior estabilidade e credibilidade para o país, haja vista o caráter técnico e a proteção quanto a influências político-partidárias, com o claro intuito de atrair investimentos estrangeiros.

$\mathrm{Na}$ ótica de Aragão, as agências reguladoras surgiram no Brasil como uma reação ao alto crescimento da máquina pública, decorrente do modelo de Estado Social vivenciado no século passado, bem como em face da pluralidade e complexidade da sociedade hodierna, inclusive sob o ponto de vista tecnológico, cuja dinâmica demanda respostas rápidas e tecnicamente especializadas por parte do Poder Público, verdadeiro corolário do princípio da eficiência. Todavia, isso estaria "muito longe de significar que sejam por essência um instrumento de desregulação ou da desestatização" (ARAGÃO, 2013, p. 274), pois foram criadas diversas "agências reguladoras, não mais de serviços públicos, mas de atividades econômicas stricto sensu, que propiciaram um aumento da intervenção estatal sem precedentes nesses setores" (ARAGÃO, 2013, p. 274).

Nesse contexto, a Constituição Federal de 1988 deu início a um processo de abertura do mercado interno ao capital estrangeiro. Posteriormente, no curso da década de 1990, foi editado o Plano Diretor de Reforma do Aparelho do Estado, voltado para a redução do tamanho da máquina estatal, dando início a um processo de desestatização da Administração Pública, concretizado pela Lei 9.491/1997 (Programa Nacional de Desestatização - PND).

Definiu-se como um dos objetivos fundamentais dessa lei a reordenação da posição estratégica do Estado na economia, transferindo à iniciativa privada atividades que vinham 
sendo exploradas pelo setor público, deixando com o setor privado a atuação direta na economia, de modo que o Estado concentrasse esforços em questões nas quais sua presença fosse indispensável para a consecução das prioridades nacionais.

As alterações promovidas na Constituição de 1988 pela Reforma Administrativa, em meados da década de 1990, trouxe previsão expressa acerca da criação de agências reguladoras em duas oportunidades, apontadas pela doutrina como seu fundamento constitucional (CAL, 2003, p. 83-84). A nova redação dada pela Emenda Constitucional $\mathrm{n}^{\mathrm{o}}$ 8, de 15.8.1995, ao inciso XI do artigo 21, que dispõe acerca da exploração de serviços de telecomunicações, previu a criação de órgão regulador e, na mesma linha, o inciso III do $\S 2^{\circ}$ do artigo 177, inserido pela Emenda Constitucional $n^{\circ}$ 9, de 9.11.1995, previu a criação de órgão regulador do monopólio da União.

Com essa transferência de atividades, tendente a reduzir o tamanho da máquina estatal e a conferir conotação mais liberal à economia, fez-se a opção por criar entidades administrativas independentes, as quais passaram a desempenhar este papel regulatório de controle e disciplina normativa (CUÉLLAR, 2001, p. 64), notadamente sobre as atividades relacionadas à prestação de serviços públicos decorrentes da quebra de monopólios.

Reforça-se que, não obstante a influência liberal nesse processo de contração da intervenção direta do Estado, já não se admitia a opção pura e simples pelo não intervencionismo; portanto, não há que se falar em retorno ao modelo liberal clássico, conforme observa Binenbojm (2006, p. 249):

\begin{abstract}
a transferência de serviços públicos e/ou de sua execução à iniciativa privada não poderia conduzir a um Estado puramente liberal, guiado pelo nãointervencionismo. Daí as agências constituírem também efeito da reforma por que passou o Estado brasileiro, na medida em que foram institucionalmente incumbidas da regulação tanto de serviços públicos desestatizados como de outras atividades econômicas de relevante interesse social, devolvidas total ou parcialmente à iniciativa privada.
\end{abstract}

A efetiva criação das agências reguladoras brasileiras, no âmbito federal, se deu através de legislações específicas, quais sejam: a) Agência Nacional de Energia Elétrica ANEEL, Lei 9.427/1996; b) Agência Nacional de Telecomunicações - ANATEL, Lei 9.472/1997; c) Agência Nacional de Petróleo - ANP, Lei 9.478/1997; d) Agência Nacional de Vigilância Sanitária - ANVISA, Lei 9.782/1999; e) Agência Nacional de Saúde Suplementar - ANS, Lei 9.961/2000; f) Agência Nacional de Águas - ANA, Lei 9.984/2000; g) Agência Nacional de Transportes Terrestres - ANTT, Lei 10.233/2001; h) Agência Nacional de 
Transportes Aquaviários - ANTAQ, Lei 10.233/2001; i) Agência Nacional de Cinema ANCINE, Medida Provisória 2.219/2001; j) Agência Nacional de Aviação Civil - ANAC, Lei $11.182 / 2005$.

Ventila-se também que a Comissão de Valores Mobiliários - CVM enquadra-se no rol das agências reguladoras, notadamente após a edição da Lei 10.441/2002, que conferiu maior autonomia à sua atuação. Todavia, menciona Aragão que esta autarquia, assim como o Banco Central do Brasil, não detém a mesma independência outorgada às agências reguladoras perante o Poder Executivo (ARAGÃO, 2013, p. 272).

\title{
3 A ATIVIDADE REGULATÓRIA DO ESTADO E SEUS FUNDAMENTOS
}

\subsection{A REGULAÇÃO ESTATAL}

A atividade regulatória desenvolvida pelo Estado representa uma mudança de paradigma em sua organização e atuação. Tal modelo desponta como uma alternativa à atuação direta sobre o domínio econômico, o que implicou uma tendência de desregulamentação, entendida como o arrefecimento de rígidas normas a impor condutas aos atores econômicos e a adoção de uma nova sistemática (mais flexível) de criação de normas.

Sobre o tema, opina Miragem (2013, p. 85):

\begin{abstract}
Neste sentido, regulação econômica nesta versão atualizada é resultado das tendências de diminuição do Estado (mediante privatização) e da desregulamentação do Mercado, aqui entendido como diminuição das normas rígidas (legais/regulamentares) de imposição de condutas dos agentes econômicos, em favor de um modelo regulador em que a produção normativa seja flexível, sob permanente revisão e atualizada em face das necessidades e rápidas transformações da economia. E da mesma forma, um modo de produção normativa diferenciado, mediante participação dos interessados no processo de decisão normativa estatal, e o aporte de interesse, sugestões e críticas sobre as propostas de regulação.
\end{abstract}

Essa feição adotada pelo Estado reformula a compreensão acerca da atividade administrativa, pois deixa de recair sobre o Poder Público o dever de prestar diretamente diversos serviços públicos. Denomina-se de princípio da subsidiariedade (MOREIRA NETO, 2006, p. 365) esse arrefecimento da atuação estatal (que deixa de ser prestador para ser regulador) e a consequente transferência para os particulares de atividades que podem ser por 
eles desenvolvidas com ganho de eficiência, seja no âmbito da livre-iniciativa, seja sob regime de direito público (serviços públicos universais), submetidos à regulação em ambos os casos (SOUTO, 2005, p. 35).

Num regime de mercado e livre-iniciativa, o exercício de atividades, sobretudo as de natureza econômica, deve recair preferencialmente sobre os indivíduos, de maneira que a atuação do Estado encontra-se vinculada à noção de subsidiariedade. Miragem (2013, p. 86) conceitua o princípio da subsidiariedade como um "limite vertical, indicando o caráter supletivo da regulação, de modo a que esta tenha lugar apenas para complementar ou suplementar a realidade dada pelos entes regulados, quando estes por si não alcancem atender às necessidades sociais".

Neste sentir, ainda que transferido o exercício de determinadas atividades, remanesce com o Poder Público o dever de zelar pela consecução do interesse público envolvido, o que será feito por meio da função regulatória, assim conceituada por Aragão (2013, p. 40):

podemos condensadamente definir a regulação estatal da economia como o
conjunto de medidas legislativas, administrativas, convencionais, materiais
ou econômicas, abstratas ou concretas, pelas quais o Estado, de maneira
restritiva da autonomia empresarial ou meramente indutiva, determina,
controla ou influencia o comportamento dos agentes econômicos, evitando
que lesem os interesses sociais definidos no marco da Constituição e os
orientando em direções socialmente desejáveis.

Ademais, há de se registrar que as agências reguladoras desempenham também funções de natureza administrativa e julgadora. As administrativas são relativas ao poder de polícia que lhes é próprio (restrito, por certo, ao âmbito de sua competência setorial), de modo que fiscalizam o exercício da atividade econômica objeto da regulação, bem como a atividade do concessionário na prestação do serviço público, eventualmente impondo sanções quando do descumprimento de normas legais ou infralegais.

A função julgadora, denominada por alguns de quase judicial ou, ainda, função arbitral, presta-se a dirimir conflitos que porventura ocorram entre as empresas que atuem em determinado setor regulado ou entre essas e seus respectivos usuários, "exercendo a função decisória tal como um árbitro" (BARROSO, 2006, p. 80).

As leis de regência das agências reguladoras, regra geral, conferiram poder de decisão para tais entidades, com ênfase nos institutos da conciliação e da arbitragem, o que permite que atuem no sentido de compor conflitos entre prestadores de serviço, bem como entre estes e os cidadãos, recaindo sobre as autarquias regulatórias a posição de instância definitiva no 
âmbito administrativo, sem prejuízo da inafastabilidade do controle jurisdicional. Busca-se, assim, a criação de uma "instância decisória em que a entidade reguladora, na posição de terceiro imparcial, componha os conflitos de interesses entre os atores envolvidos na atividade regulada, apresentando a solução que melhor realize as políticas públicas para o setor" (BINENBOJM, 2006, p. 258).

No âmbito da prestação de serviços públicos, a atividade regulatória, sob o viés judicante, a dirimir conflitos entre os delegatários, está previsto na Lei 8.987/1995, que no inciso XV de seu artigo 23 já colocava o foro e o modo amigável de solução das divergências contratuais como cláusulas essenciais ao contrato de concessão, e em seu artigo 23-A, inserido pela Lei 11.196/2005, prevê a possibilidade de emprego de mecanismos privados para a resolução de disputas contratuais ou a ele relacionadas, inclusive a arbitragem.

Aragão (2013, p. 281) conceitua as agências reguladoras nos seguintes termos:

podemos conceituar as agências reguladoras independentes brasileiras como sendo as autarquias de regime especial, dotadas de considerável autonomia frente à Administração centralizada, incumbidas do exercício de funções regulatórias e dirigidas por colegiado cujos membros são nomeados por prazo determinado pelo Presidente da República, após prévia aprovação pelo Senado Federal, vedada a exoneração ad nutum.

Por fim, não é demais mencionar que a intervenção regulatória do Estado "se caracteriza pela imposição, por norma legal, de prescrições positivas e negativas sobre o desempenho de atividades econômicas ou sociais privadas, visando à prevalência de interesses públicos específicos legalmente definidos" (MOREIRA NETO, 2006, p. 129), o que sintetiza a capacidade normativa que lhe é inerente.

Em suma, a regulação estatal apresenta-se como uma figura híbrida, uma mescla de atribuições de várias naturezas, que se concentram num único órgão (agência reguladora): informativa, fiscalizadora, negociadora, normativa, gerencial, arbitradora, sancionadora e judicante (MOREIRA NETO, 2006, p. 392). Essencialmente, sua finalidade é harmonizar o interesse público com os direitos dos particulares, agindo no sentido de prevenir, controlar ou corrigir eventuais consequências negativas em setores legalmente considerados críticos. 


\subsection{FUNDAMENTOS DA ATIVIDADE REGULATÓRIA NO BRASIL}

A regulação estatal pode ser compreendida em sentido amplo (como toda atividade do Estado sobre o domínio econômico, ressalvada a intervenção direta) e em sentido estrito (refere-se a uma intervenção estatal específica no domínio econômico, que se desenvolve mediante a definição de regras e critérios técnicos, com o fim de alcançar interesse público). As agências reguladoras enquadram-se na segunda acepção.

Trilhar o caminho da intervenção prioritariamente indireta é característica do modelo de Estado Regulador hodiernamente vivenciado, de maneira que seus esforços ficam concentrados na produção de normas e decisões no âmbito dos setores regulados, mantendose apenas o desempenho material e direto de reduzidas atividades, sobretudo aquelas com caráter essencial (JUSTEN FILHO, 2014, p. 672).

Para executar a atividade regulatória, optou-se pela sistemática da descentralização, por meio da criação de entidades da Administração Pública indireta, dotadas de personalidade jurídica própria, sob a forma de autarquias em regime especial, sem subordinação hierárquica ao ente político ao qual estejam vinculadas.

Cada ente foi criado para atuar num âmbito setorial específico (econômico ou social), sendo marcantes as características de especialização e de atuação setorizada. A finalidade das agências reguladoras é mencionada por Moreira Neto (2014, p. 896), que enaltece tais aspectos:

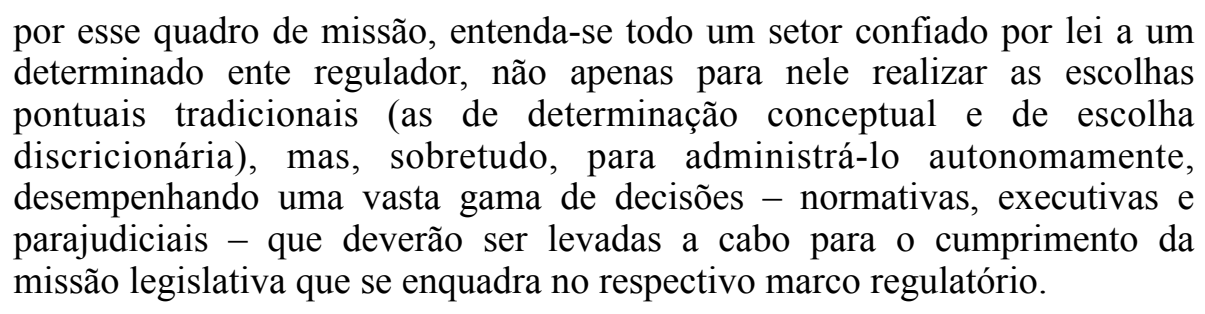

A necessidade de especialização da atividade regulatória, a abranger a natureza técnica que lhe é inerente, bem como a outorga de competência normativa encontram respaldo na sociedade complexa e dinâmica que hoje se vivencia, a qual demanda respostas rápidas e precisas do Estado. Conforme observa Miragem (2013, p. 76), o argumento que dá sustentação à atividade regulatória "é a necessidade de especialização técnica para bem produzir normas aplicáveis a determinados setores econômicos, de modo a ter domínio 
técnico sobre o objeto da regulação", o que se faz por meio de uma entidade criada para atuar em setor específico.

Cumpre frisar que, na qualidade de autarquias, definidas pelo Decreto-Lei 200/1967 como serviço autônomo, criado por lei, com personalidade jurídica, patrimônio e receita próprios, para executar atividades típicas da Administração Pública, que requeiram, para seu melhor funcionamento, gestão administrativa e financeira descentralizada, as agências reguladoras submetem-se a regime jurídico de Direito Público, permitindo o desempenho de atividades típicas da Administração Pública.

A descentralização, mediante a criação de entes especializados em determinado setor, tem o objetivo de aperfeiçoar a atuação administrativa, tornando-a mais eficiente, e de restringir a burocratização ao patamar mínimo necessário para o cumprimento de seus fins. Conforme observa Aragão (2013, p. 213), a complexidade que se observa tanto no Direito Administrativo quanto na própria sociedade vem exigindo que a atuação da Administração Pública nos dias atuais seja baseada numa perspectiva descentralizante, devidamente acompanhada de uma coordenação com o Poder Central.

Não se pode olvidar que a submissão ao regime jurídico de Direito Público traz para as agências a aplicação de todos os princípios insculpidos no caput do artigo 37 da Constituição, dentre os quais o princípio da impessoalidade, segundo o qual a Administração Pública não pode criar privilégios ou favoritismos a quaisquer interesses dos particulares.

Decorre daí o dever de neutralidade, que atrai para as agências reguladoras a necessidade de promover o interesse público, jamais direcionando suas ações para a realização de interesses particulares.

Do respeito ao princípio da impessoalidade, neste particular, resulta que não pode o regulador, sob qualquer pretexto, dispor das normas e demais decisões do órgão em favor de interesses parciais dos agentes econômicos regulados, ou mesmo de interesses específicos de usuários ou do Poder Concedente, que não se conformem com o interesse geral a ser perseguido pelos órgãos regulatórios. Resta subjacente ao princípio da impessoalidade o equilíbrio de interesses que preside a atividade de regulação (MIRAGEM, 2013, p. 80).

A intervenção indireta no domínio econômico, perpetrada pelas autarquias regulatórias, deve pautar-se por questões de ordem técnica, sem pretender realizar objetivos de cunho meramente político, bem como sem conferir qualquer tipo de privilégio a particulares. Marques Neto (2005, p. 50) diz tratar-se “da necessária neutralidade 
(equidistância) que o ente regulador deve manter em face dos interesses regulados, incluídos aí também os interesses do Poder Público".

Nessa linha, as agências reguladoras demandam uma neutralidade política na gestão da atividade administrativa que desempenham, pautando-se prioritariamente por critérios técnicos, o que não significa dizer que a regulação ocorrerá em desfavor de quaisquer das partes envolvidas no processo regulatório, mas tão somente que as decisões demandam uma equidistância do ente competente para exercê-la (MARQUES NETO, 2005, p. 51).

Consequentemente, a neutralidade requer que a atividade regulatória seja exercida com equilíbrio, "traduzido na mediação, sopesamento e interlocução entre os vários interesses existentes no setor regulado" (MARQUES NETO, 2005, p. 49). Noutras palavras, a interação com atores envolvidos no processo regulatório apresenta-se como um dos fundamentos da regulação, na medida em que o diálogo será um fator de legitimação da intervenção estatal na ordem econômica (MARQUES NETO, 2005, p. 32).

É marcante, ainda, o atributo da independência, também denominado de autonomia reforçada, considerado o principal fundamento das agências reguladoras e que se manifesta através de quatro vieses diferentes: político, técnico-decisional, administrativo (gerencial, orçamentário e financeiro) e normativo.

Nesse sentido, Binenbojm aponta a independência como a principal característica do regime especial das agências reguladoras, que pode ser subdividida em quatro diferentes aspectos: (a) independência política dos dirigentes, pois possuem estabilidade durante seus respectivos mandatos, ou seja, é vedada a exoneração ad nutum pelo Presidente da República; (b) independência técnica decisional, o que afastaria o cabimento de recurso hierárquico impróprio; (c) independência gerencial, orçamentária e financeira ampliada; e (d) independência normativa (BINENBOJM, 2006, p. 252).

A independência política, vinculada à sistemática de escolha e à estabilidade temporária dos dirigentes (vedação à exoneração ad nutum), reflete o necessário distanciamento do órgão regulador em relação aos atos que compõem o setor regulado, incluindo-se o próprio Estado. A independência técnico-decisional reflete o caráter eminentemente técnico de sua atuação, conferindo conotação específica à independência política. A seu turno, a independência gerencial, orçamentária e financeira presta-se a 
fortalecer uma atuação isenta das agências, assegurando autonomia administrativa aos seus dirigentes e a existência de orçamento próprio.

Já a independência normativa pode ser qualificada como o principal atributo da regulação. A essência das agências é a capacidade para editar normas de caráter técnico no âmbito do setor que se prestam a regular. Tal outorga de competência é feita diretamente pelo Legislativo, que retira determinada matéria do domínio da lei, passando-a ao domínio do regulamento, o que se denomina de deslegalização ou delegificação. Os regulamentos são dotados de normatividade e têm o intuito de disciplinar a atuação de particulares, seja no exercício de atividades econômicas, seja no desempenho de serviços públicos.

Moreira Neto (2006, p. 165) registra que a independência, analisada sob essas quatro diferentes vertentes, revela-se como garantia indispensável ao exercício politicamente neutro da função de regulação.

Por fim, em apertada síntese, é possível dizer que a atividade regulatória do Estado tem como fundamentos: (a) atuação setorial; (b) neutralidade/equidistância em relação aos interesses regulados; (c) caráter eminentemente técnico; e (d) independência/autonomia reforçada. Atualmente, acredita-se ser mais adequada a intervenção indireta do Estado no domínio econômico e, ao mesmo tempo, que esta se proceda por meio de entidades autônomas, politicamente independentes e com especialização técnica, a fim de que a regulação seja realizada com a necessária neutralidade e imparcialidade, colocando-se em postura equidistante em relação aos diversos atores que compõem o respectivo setor regulado.

\subsection{DISCRICIONARIEDADE TÉCNICA}

Tendo em vista que as agências reguladoras devem lastrear suas decisões (primordialmente) em critérios de ordem técnica, faz-se necessário abordar a questão da discricionariedade técnica, que é uma das formas de atuação do Poder Público.

A discricionariedade é compreendida como um poder jurídico limitado a parâmetros legais, de maneira que toda ação administrativa somente se justifica com a existência do correspondente amparo legal (DI PIETRO, 2007, p. 38); nesse contexto, a discricionariedade representa uma margem de liberdade, prevista em lei, para a atuação do administrador 
público. Sob esta perspectiva, os atos administrativos discricionários caracterizam-se pela liberdade de atuação dentro da margem definida pelo legislador, de forma que a própria lei acolhe mais de uma atuação legítima/possível a ser adotada pelo administrador público, todas elas válidas para o direito (DI PIETRO, 2014, p. 221).

O fortalecimento da ideia de discricionariedade vincula-se à constatação da impossibilidade de que o legislador seja capaz de dispor previamente acerca de todas as situações em que a Administração Pública figure como interessada, bem como em virtude de novas situações com as quais o Poder Público venha a se deparar, notadamente aqueles casos que exigem uma resposta rápida.

Por outro lado, é importante destacar que o princípio da legalidade administrativa passou por mais uma revisitação teórica, haja vista o processo de constitucionalização do Direito Administrativo, de modo que a Administração Pública não se encontra vinculada apenas à lei, mas principalmente aos ditames constitucionais. Paulatinamente, a noção de vinculação positiva da Administração Pública à lei vem perdendo força no ordenamento jurídico pátrio e a máxima “administrar é aplicar a lei de ofício” já não se compatibiliza com a sociedade atual, essencialmente complexa e dinâmica.

Ganhou espaço a construção dos textos legais permeados por cláusulas gerais e conceitos jurídicos indeterminados, com a definição de standards que orientam a realização de um fim, de maneira que a solução deixa de ser atribuída diretamente pelo legislador e passa a recair sobre o aplicador da norma. Assim, "os textos legais se caracterizam cada vez mais por conceitos indeterminados, enumeração de exemplos e cláusulas gerais, além de estabelecerem meros critérios materiais de ponderação para a tomada das decisões individuais mediante fixação de fins e objetivos" (KRELL, 2013, p. 15).

A abertura normativa proporcionada pelos conceitos jurídicos indeterminados, assim como ocorre nos casos de discricionariedade, confere maior liberdade para a Administração Pública, outorgando-lhe poder de decisão. Não há como dissociar a análise dos conceitos jurídicos indeterminados e da discricionariedade administrativa. Conforme anota Krell (2013, p. 48), “conceitos indeterminados e discricionariedade são fenômenos interligados, visto que, muitas vezes, o órgão administrativo deve lançar mão desta para poder preencher aqueles".

$\mathrm{Na}$ sociedade que se vivencia atualmente vislumbra-se uma necessidade de conferir à Administração Pública o poder de construir a decisão mais adequada para o caso concreto. 
Para tanto, o Legislativo passou a criar textos normativos que definem um fim a ser alcançado, deixando ao Executivo a escolha acerca das medidas e caminhos que serão adotados nesse processo.

Krell (2013, p. 18) ressalta, ainda, que "uma excessiva reserva de lei entra em choque com o princípio da divisão equilibrada dos Poderes e menospreza a legitimação democrática dos outros órgãos do Estado". Por esta razão, não é vedado ao legislador "deixar ao Governo e à Administração Pública a regulamentação de importantes aspectos materiais e formais, quando a temática justificar ou até exigir tal delegação".

A abertura normativa proporcionada pelas normas veiculadoras de competências discricionárias, bem como aquelas que são compostas por conceitos jurídicos indeterminados, por vezes, não são apenas possíveis, mas necessárias, a depender da complexidade das questões envolvidas ou da existência de mais de uma solução possível, circunstâncias que somente poderão ser adequadamente valoradas caso a caso (KRELL, 2013, p. 18).

Não é demais pontuar que as normas veiculadoras de conceitos jurídicos indeterminados, diante do caso concreto, podem produzir zonas de certeza positivas, em que o conceito veiculado pela lei é facilmente identificado, zonas de certeza negativas, em que se elimina completamente sua aplicação, e zonas de penumbra, gerando dúvidas acerca de sua aplicação. Para Germana Moraes (2004, p. 66), é inegável “que a aplicação de normas jurídicas que contêm conceitos indeterminados tanto pode conduzir à certeza quanto à incidência da norma ao caso concreto (única solução possível), como pode ensejar dúvidas no momento da concretização", sempre que inexistir certeza quanto a adequação do fato à previsão normativa abstrata (mais de uma alternativa comportada pela norma).

Contudo, essa liberdade conferida à Administração Pública não pode ser entendida como ilimitada e infensa ao controle jurisdicional. Ao conferir ao Executivo uma margem de atuação mais elástica, o Legislativo não recusa a necessidade de observância das normas constantes do ordenamento jurídico, em especial dos mandamentos constitucionais.

A Constituição Federal de 1988 prevê expressamente a inafastabilidade do controle jurisdicional e os conceitos jurídicos indeterminados não importam em supressão dessa garantia constitucional. Porém, seu exercício deverá dar-se com parcimônia, não só porque recai sobre o Executivo a competência e a legitimidade para conduzir os desígnios estatais, realizando escolhas de cunho político, mas também porque não se busca a mera substituição 
de escolhas, ou seja, não se trata de meramente substituir a vontade do Executivo pela vontade do Judiciário. A tomada de uma decisão, devidamente fundamentada, sobretudo aquela amparada em questões de ordem técnica, motivada de forma adequada e satisfatória, precisa receber uma presunção favorável acerca de seu juízo.

Noticia Di Pietro (2007, p. 112) que, no direito italiano, procede-se à análise dos conceitos jurídicos indeterminados a partir de uma distinção entre discricionariedade administrativa, que seria a discricionariedade propriamente dita, e discricionariedade técnica, que receberia a marca de discricionariedade imprópria. Essa diferenciação conceitual surge com o austríaco Bernatzik, que inaugura a ideia de discricionariedade técnica.

Originalmente, percebia-se a discricionariedade técnica como um âmbito de decisão relativo a questões de elevada complexidade técnica e imune ao controle judicial, de maneira que competiria à Administração Pública, diante do caso concreto, avaliar a medida mais adequada a ser adotada, lastreada em conhecimentos técnico-científicos, sendo sua a última palavra sobre a questão.

A discricionariedade técnica, segundo leciona Di Pietro, pode apresentar-se de diferentes formas, interferindo na margem de liberdade de decisão do administrador público. Há casos em que a decisão administrativa sobrepõe-se às de natureza técnica, bem como existem outras situações em que a margem de liberdade administrativa é completamente mitigada, uma vez que a definição de questões técnico-científicas pelo órgão competente acarreta a impossibilidade de o gestor público valorar de forma diversa, exigindo-se que adote a decisão de acordo com parâmetros definidos em lei, de modo que em tais circunstâncias "não existe discricionariedade propriamente dita, porque a Administração não tem liberdade para apreciar a oportunidade e a conveniência do ato" (DI PIETRO, 2007, p. 114).

Posicionamento interessante é perfilhado por Sérgio Guerra (2009), que traz a ideia de previsibilidade técnica, entendida como "parâmetro mitigador dos riscos do arbítrio, [...] importante remédio contra as decisões casuísticas", ou seja, é a "escolha administrativa como instrumento funcionalmente ligado à criação de clareza e previsibilidade", com o fim de evitar insegurança jurídica.

Justen Filho (2014, p. 253), adotando entendimento segundo a qual a expressão discricionariedade técnica é utilizada "para indicar aquelas situações em que a lei determina que a solução no caso concreto seja norteada pelo conhecimento técnico-científico", ressalta 
que em tais casos a norma não autoriza a realização de escolhas de natureza política, haja vista que a decisão deverá vincular-se às valorações técnico-científicas. Todavia, o próprio autor reconhece a dificuldade de caracterizar essa atuação como vinculada, como pretende parcela da doutrina, notadamente porque "nenhuma ciência pode gerar aplicações práticas absolutamente precisas, uniformes e destituídas de alternativas ou dúvidas”.

A ideia de discricionariedade técnica possui três interessantes justificativas no plano fático: a) em primeiro lugar, o Poder Legislativo, na qualidade de órgão político e, em regra, sem conhecimento científico para tanto, não poderia adentrar a disciplina de questões de natureza técnica; b) o conhecimento científico evolui constantemente, podendo ser rapidamente objeto de importantes mudanças, o que tornaria a legislação obsoleta; c) finalmente, não se mostra conveniente predefinir uma solução para situações que a ciência encontra situações diversas em cada caso concreto. Por conseguinte, passa para a Administração Pública, mais próxima das situações do cotidiano, a atribuição de adotar a decisão mais coerente com a circunstância fática apresentada, orientada pelo conhecimento técnico-científico pertinente.

Contudo, a existência de valoração técnico-científica dificilmente implicará solução única, seja pela existência de mais de uma alternativa viável, seja pela presença de algum componente político da construção da decisão, de maneira que se busca por meio da discricionariedade técnica que a ciência torne possível a concretização de um interesse público, ainda que existam opções plausíveis. Em casos tais, procede-se à delimitação das alternativas possíveis, mas nem sempre haverá uma completa eliminação das escolhas.

Exemplificativamente, é possível citar a definição da taxa básica de juros pelo Banco Central, decisão que se baseia em critérios técnicos, mas que dificilmente gera consenso entre os economistas, ou, ainda, a caracterização da invalidez para fins de aposentadoria, que igualmente pode gerar controvérsias no meio médico.

No que diz respeito às agências reguladoras, não se pode olvidar que o poder normativo configura-se como um dos mais importantes mecanismos de atuação, o qual se justifica pela necessidade de disciplinar questões de natureza técnica em setores específicos e complexos, questões estas que dificilmente poderiam ser avaliadas e regradas por normas editadas pelo Poder Legislativo. 
Quanto ao caráter técnico da atuação das agências, Aragão (2013, p. 343-344) relata que a legislação impõe, em primeiro lugar, a formação de um corpo de pessoal capacitado, com conhecimento técnico e científico no setor regulado, e o aprofundamento nas diversas questões a serem reguladas por meio de estudos específicos. Em segundo, que a técnica dificilmente será capaz de fornecer soluções únicas, remanescendo uma margem de liberdade para a atuação da Administração Pública (componente político), que poderá escolher entre mais de uma solução tecnicamente aceitável.

Krell (2013, p. 69) menciona a utilização do conceito discricionariedade técnica no âmbito das agências reguladoras, ao exercerem suas respectivas competências normativas, para ressaltar que este não deve ser adotado com a intenção de conferir maior isenção à atuação administrativa, mediante a presunção de neutralidade e eficiência, sem que isso guarde a devida correspondência com o plano fático, o que implicaria a ampliação da margem de liberdade das autarquias regulatórias e limitaria o controle jurisdicional.

Ainda que se baseiem em análises técnicas, a regulação nem sempre conseguirá construir grandes zonas de certezas (positivas e negativas), de modo que não se elimina a discricionariedade, apenas há uma maior delimitação da formação do juízo de valor acerca do entendimento formulado pela Administração. É possível vislumbrar, ainda, a aptidão de adoção de mecanismos de participação e controle social no processo de construção da decisão da agência reguladora como mais um fator de construção da atuação administrativa.

Em continuidade, o citado autor enfatiza a necessidade da precisa delimitação dessa atuação, a fim de evitar o arbítrio, bem como que devem submeter-se ao controle jurisdicional (ROMAN, 2013, p. 179). Se, de um lado, o autor conclui pela "existência de uma discricionariedade técnica na regulação da Ordem Econômica, que está relacionada à indispensável previsão legal mediante o recurso a conceitos flexíveis ou fluidos" (ROMAN, 2013, p. 184), de outro, o controle jurisdicional seria perfeitamente possível, mas de forma equilibrada, no sentido de que não ser admissível a mera substituição da vontade da Administração pela vontade do Judiciário (ROMAN, 2013, p. 185).

A atuação das agências reguladoras demanda um juízo técnico acerca das diversas questões objeto da regulação. A abertura normativa conferida pela adoção de conceitos jurídicos indeterminados e pela outorga de discricionariedade, ainda que acompanhadas de avaliações de ordem técnica, faz com que remanesça uma margem de liberdade na atuação 
das autarquias regulatórias. Não se afasta, assim, a possibilidade de controle jurisdicional, mesmo que não se admita a mera substituição da vontade do Executivo pela vontade do Judiciário. O controle deverá respeitar os conceitos técnico-científicos adotados, mas poderá ser realizado com base na juridicidade, a fim de averiguar se foram respeitadas as normas constitucionais, bem como as finalidades elencadas nas normas instituidoras das agências.

\section{CONSIDERAÇÕES FINAIS}

O intuito do presente trabalho recaiu sobre a análise dos fundamentos da regulação estatal, sem olvidar a necessidade de uma contextualização histórica da consolidação das agências reguladoras no plano internacional e no Brasil.

As agências reguladoras surgem por meio da descentralização, em que entidades são criadas para atuar em setores específicos, levando em consideração que a especialização, aliada ao caráter eminentemente técnico da agência, tende a tornar mais eficientes as ações e decisões por ela adotadas.

Com efeito, além de uma atuação descentralizada, especializada e técnica, a função regulatória demanda também uma autonomia reforçada, também denominada de independência, que se reveste de quatro aspectos: independência política, técnico-decisional, administrativa (gerencial, orçamentária e financeira) e normativa os aspectos mais marcantes da regulação.

Tais facetas da independência das agências reguladoras têm por finalidade assegurar que a atividade regulatória do Estado seja desenvolvida de forma neutra, sem favorecer os atores do setor regulado e de modo a blindar as atuações de seus dirigentes de eventuais pressões exercidas por agentes políticos, o que se conforma como verdadeira garantia dos administrados.

\section{REFERÊNCIAS}

ARAGÃO, Alexandre Santos de. Agências Reguladoras e a Evolução do Direito Administrativo Econômico. 3. ed. Rio de Janeiro: Forense, 2013. 
AUAD, Denise. Autoridades Administrativas Independentes na França. In: DI PIETRO, Maria Sylvia Zanella (org.). Direito Regulatório: temas polêmicos. Belo Horizonte: Fórum, 2004.

BADIN, Luiz Armando. As Autoridades Administrativas Independentes na França: Finalidades Institucionais e Meios de Atuação. In: DI PIETRO, Maria Sylvia Zanella (org.). Direito Regulatório: temas polêmicos. Belo Horizonte: Fórum, 2004.

BARROSO, Luís Roberto. Agências Reguladoras. Constituição, Transformações do Estado e Legitimidade Democrática. In: BINENBOJM, Gustavo (coord.). Agências Reguladoras e Democracia. Rio de Janeiro: Lumen Juris, 2006.

BINENBOJM, Gustavo. Uma Teoria do Direito Administrativo. Rio de Janeiro: Renovar, 2006.

BURNHAM, William. Introduction to the Law and Legal System of the United States. 4th ed. West, 2006.

CAL, Arianne Brito Rodrigues. As Agências Reguladoras no Direito Brasileiro. Rio de Janeiro: Renovar, 2003.

CUÉLLAR, Leila. As Agências Reguladoras e seu Poder Normativo. São Paulo: Dialética, 2001.

CUSTOS, Dominique. La Noción Estadounidense de Regulación. In: MARCOU, Gérard; MODERNE, Franck (org.). Derecho de la regulación, los servicios públicos y la integración regional. Tomo I. Bogotá: Editorial Universidad de Rosario, 2009.

DI PIETRO, Maria Sylvia Zanella. Discricionariedade administrativa na Constituição de 1988. 2. ed. São Paulo: Atlas, 2007.

GOMES, Joaquim Barbosa Gomes. Agências Reguladoras: A "Metamorfose" do Estado e da Democracia. In: BINENBOJM, Gustavo (coord.). Agências Reguladoras e Democracia. Rio de Janeiro: Lumen Juris, 2006.

GUERRA, Sérgio. Redução da Discricionariedade Administrativa por meio da Previsibilidade Técnica. Revista Eletrônica de Direito Administrativo Econômico (REDAE), Salvador, Instituto Brasileiro de Direito Público, $\mathrm{n}^{0}$ 20, novembro/dezembro/janeiro, 2009/2010. Disponível em: < http://www.direitodoestado.com/revista/REDAE-20-NOVEMBRO-2009SERGIO-GUERRA.pdf $>$. Acesso em: 5/5/2015.

JUSTEN FILHO, Marçal. Curso de Direito Administrativo. 10. ed. São Paulo: Revista dos Tribunais, 2014.

KRELL, ANDREAS J. Discricionariedade Administrativa e Conceitos Legais Indeterminados. 2. ed. Porto Alegre: Livraria do Advogado, 2013.

LIMA, Gustavo Augusto F. de. Agências Reguladoras e o Poder Normativo. São Paulo: Baraúna, 2013.

MARCOU, Gérard. La regulación e los servicios públicos. Las enseñanzas del derecho comparado. In: MARCOU, Gérard; MODERNE, Franck (org.). Derecho de la regulación, los servicios públicos y la integración regional. Tomo I. Bogotá: Editorial Universidad de Rosario, 2009. 
MARQUES NETO, Floriano de Azevedo. Agências Reguladoras Independentes Fundamentos e seu Regime Jurídico. Belo Horizonte: Forum, 2005.

MESSITTE, Peter J. O Direito Administrativo nos Estados Unidos. Revista Justiça \& Cidadania. Edição $n^{\circ}$ 177. Disponível em <http://www.editorajc.com.br/2015/05/o-direitoadministrativo-nos-estados-unidos/>. Acesso em: 8/3/2016.

MIRAGEM, Bruno. A Nova Administração Pública e o Direito Administrativo. 2. ed. São Paulo: Revistas dos Tribunais, 2013.

MODERNE, Franck. Los usos de la noción de "regulación" em el derecho positivo y em la doctrina jurídica. In: MARCOU, Gérard; MODERNE, Franck (org.). Derecho de la regulación, los servicios públicos y la integración regional. Tomo I. Bogotá: Editorial Universidad de Rosario, 2009.

MORAES, Germana de Oliveira. Controle Jurisdicional da Administração Pública. São Paulo: Dialética, 2004.

MOREIRA NETO, Diogo de Figueiredo. Curso de Direito Administrativo. 16. ed. Rio de Janeiro: Renovar, 2014.

. Mutações do Direito Público. Rio de Janeiro: Renovar, 2006.

MOTTA, Paulo Roberto Ferreira. Agências Reguladoras. Barueri: Manole, 2003.

POSNER, Eric A.; VERMEULE, Adrian. Interring the Nondelegation Doctrine. University of Chicago Law Review. Disponível em <http://www.ericposner.com/ Interring\%20the\%20Nondelegation\%20Doctrine.pdf>. Acesso em: 10/3/2016.

ROMAN, Flávio José. Discricionariedade Técnica na Regulação Econômica. São Paulo: Saraiva, 2013.

SOUTO, Marcos Juruena Villela. Direito Administrativo Regulatório. Rio de Janeiro: Lumen Juris, 2005.

SUPREMA Corte dos EUA. Chevron U.S.A., Inc. v. NRDC, 467 U.S. 837 (1984). Disponível em: < https://supreme.justia.com/cases/federal/us/467/837/case.html>. Acesso em: $1 / 3 / 2016$.

SZAPIRO, Manuel. Las agencias reguladoras europeas: perspectiva institucional. Disponível em: <http://app.vlex.com/\#/vid/agencias-reguladoras-europeasinstitucional-44666425>. Acesso em: 15/12/2015. 